\title{
Intramedullary spinal cord and intraventricular astrocytoma of varied pathology and molecular features in a teenager
}

\author{
Yan Yuen Lo, ${ }^{1}$ Denise Malicki, ${ }^{2}$ Michael Levy, ${ }^{3}$ John Ross Crawford ${ }^{4}$
}

${ }^{1}$ Neurosciences, University of California San Diego, La Jolla, California, USA

2Pathology, Rady Children's Hospital University of California San Diego, San Diego,

California, USA

${ }^{3}$ Neurosurgery, University of California San Diego, San Diego, California, USA

${ }^{4}$ Neurosciences and Pediatrics, University of California San Diego, La Jolla, California, USA

Correspondence to Dr John Ross Crawford; jrcrawford@ucsd.edu

Accepted 14 December 2021
Check for updates

(c) BMJ Publishing Group Limited 2022. No commercial re-use. See rights and permissions. Published by BMJ.

To cite: Lo YY, Malicki D, Levy M, et al. BMJ Case Rep 2022:15:e248249. doi:10.1136/bcr-2021248249

\section{DESCRIPTION}

A 16-year-old male adolescent with a medical history of autism and kyphosis presented following 2 years of worsening back pain. Neurological examination revealed a wide-based gait with diminished lower extremity reflexes and abnormal joint position/vibratory sense. MRI of the spine showed a large solid and cystic heterogeneous haemorrhagic contrast-enhancing mass in the lower thoracic spinal cord and conus between T10 and L2 (figure 1A,B). The patient underwent a near total surgical resection where pathology revealed moderately cellular proliferation of glial process-forming cells with nuclear pleomorphism, mitotic activity (four mitosis per high-powered field), eosinophilic granular bodies, myxoid background and mildly hyalinised blood vessels consistent with a histopathological diagnosis of a high-grade glioma (figure 2A). An MRI of the brain was performed to assess for disseminated disease revealing a non-enhancing cystic mass in the left foramen of Monro concerning

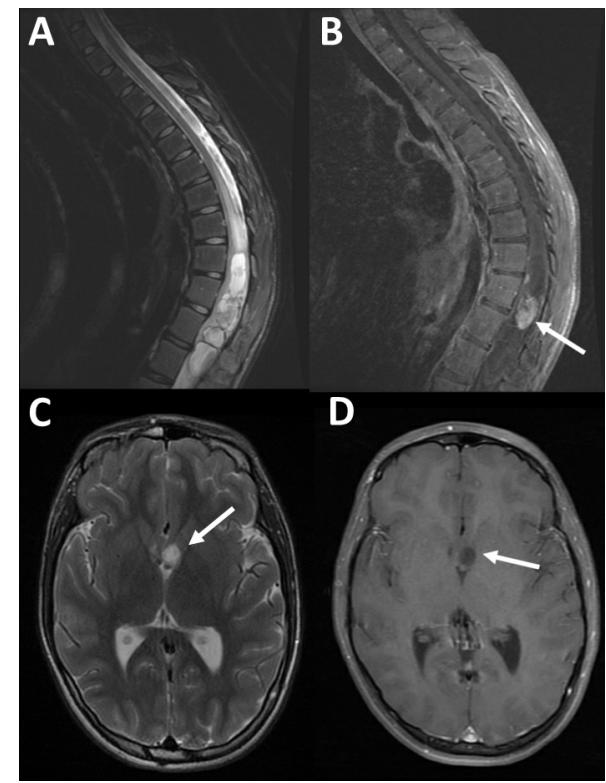

Figure 1 Neuroradiographical features of spinal cord and intraventricular low-grade glioma. Sagittal T2-weighted MRI of the spine (A) reveals a large cystic intramedullary thoracic tumour that demonstrates focal enhancement on postcontrast T1-weighted sequences (arrow) (B). MRI of the brain revealed a cystic tumour (arrow) in the region of the foramen of Monro on T2weighted sequences (C) without contrast enhancement (arrow) (D). for metastatic disease (figure 1C,D). The neuroradiographical differential diagnosis included an area of metastasis versus an unusual low-grade glioma or atypical neurocytoma. He underwent endoscopic biopsy of the intraventricular mass where pathology demonstrated a moderately cellular proliferation of small cells with round nuclear, perinuclear halos and few mitotic figures, few scattered admixed mature neurons and microcyst formations with myxoid background (figure 2B). Immunochemistry was diffusely positive for synaptophysin and glial fibrillar acid protein (not shown), consistent with a histological diagnosis of low-grade glioneuronal tumour (figure 2B).

Next-generation sequencing of the spinal cord tumour revealed a KIAA1549-BRAF fusion and microarray showed a gain of chromosome 7 with high copy gain $(5 \times) 7 \mathrm{q} 34$ (KIAA1549), gains of chromosome 5,6,14, 16p13.13-p13.12 and a loss of 22q11.21 (CLTCL1, SEPT5). Nextgeneration sequencing of the brain tumour detected no somatic variants of clinical significance and

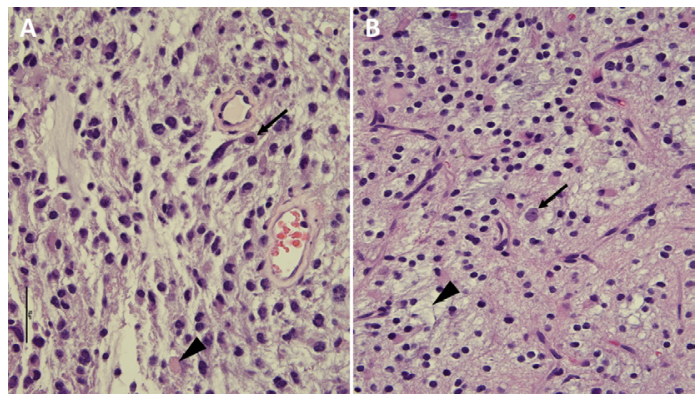

Figure 2 Pathological features of spinal cord and intraventricular low-grade glioma. Pathology of the spinal cord tumour (A) demonstrated a moderately cellular proliferation of glial process-forming cells with nuclear pleomorphism, mitotic activity (long arrow) eosinophilic granular bodies (short arrow), myxoid background and mildly hyalinised blood vessels consistent with a diagnosis of pilocytic astrocytoma with increased mitotic activity. Pathology of the intraventricular tumour (B) showed a moderately cellular proliferation of small cells with round nuclei, perinuclear halos, few mitotic figures (1 mitosis in 10 high-powered fields, not shown), few scattered admixed mature neurons (long arrow) and microcyst formation with myxoid background (short arrow). The tumour was strongly and diffusely positive for both synaptophysin and glial fibrillar acidic protein (not shown) consistent with a diagnosis of a low-grade glioneuronal tumour. 
variants of unknown significance in PDGFRA, FGFR3 and BRIP1. Microarray showed no copy number alterations. To exclude a tumour predisposition syndrome that might explain the presence of two distinct tumours, whole-genome germline testing was performed and was normal. Based on the favourable molecular features of the spinal cord tumour, an integrated molecular diagnosis of juvenile pilocytic astrocytoma with anaplastic features was rendered, and the patient underwent observation only without evidence of recurrent disease of either the spinal or intraventricular tumour more than 5 years postsurgery.

The BRAF activating mutation of KIAA1549-BRAF fusion is typically associated with paediatric low-grade glioma, and duplication of $7 \mathrm{q} 34$ has been reported as specific to juvenile pilocytic astrocytoma. ${ }^{1}$ More recently, however, KIAA1549-BRAF fusion has been reported to occur in other paediatric gliomas, including anaplastic astrocytoma. ${ }^{2}$ Furthermore, even in pilocytic astrocytoma, gain of chromosome 7 , as seen in the spinal cord tumour, can be associated with more aggressive disease. ${ }^{34}$ The histological features and genomic features support the classification of the lesion as juvenile pilocytic astrocytoma with anaplastic

\section{Learning points}

- KIAA1549-BRAF fusion is commonly associated with juvenile pilocytic astrocytoma but has been reported to occur in other paediatric gliomas, including anaplastic astrocytoma.

- Delayed diagnosis of spinal cord intramedullary tumours has been reported and longer duration of symptoms is often associated with lower-grade tumours.

- We report two distinct tumours of the brain and spinal cord with varied histological and molecular features treated with surgery alone associated with prolonged remission adding to the genetic diversity of paediatric low-grade glioma. features. The origin of the low-grade glioneuronal tumour is not entirely known. The distinct molecular and histological features compared with the spinal cord tumour do not entirely exclude the possibility of a metastatic lesion since germline sequencing did not reveal findings of a known tumour predisposition syndrome. The lack of progression of either the spinal cord or intraventricular tumour following 5 years in the absence of chemotherapy or radiation therapy confirms the lower-grade integrated diagnosis.

Our rare case of two distinct tumours of the brain and spinal cord with varied histological and molecular features treated with surgery alone associated with prolonged remission adds to the genetic diversity of paediatric low-grade glioma.

Contributors All authors were responsible for the design and writing of the case report.

Funding The authors have not declared a specific grant for this research from any funding agency in the public, commercial or not-for-profit sectors.

Competing interests None declared.

Patient consent for publication Consent obtained directly from patient(s)

Provenance and peer review Not commissioned; externally peer reviewed.

Case reports provide a valuable learning resource for the scientific community and can indicate areas of interest for future research. They should not be used in isolation to guide treatment choices or public health policy.

\section{REFERENCES}

1 Hawkins C, Walker E, Mohamed N, et al. BRAF-KIAA1549 fusion predicts better clinical outcome in pediatric low-grade astrocytoma. Clin Cancer Res 2011;17:4790-8.

2 Antonelli M, Badiali M, Moi L, et al. KIAA1549:BRAF fusion gene in pediatric brain tumors of various histogenesis. Pediatr Blood Cancer 2015;62:724-7.

3 Roth JJ, Fierst TM, Waanders AJ, et al. Whole chromosome 7 gain predicts higher risk of recurrence in pediatric pilocytic astrocytomas independently from KIAA1549-BRAF fusion status. J Neuropathol Exp Neurol 2016;75:306-15.

4 Chamdine 0 , Broniscer A, Wu S, et al. Metastatic low-grade gliomas in children: 20 years' experience at St. Jude children's research Hospital. Pediatr Blood Cancer 2016;63:62-70.

Copyright 2021 BMJ Publishing Group. All rights reserved. For permission to reuse any of this content visit https://www.bmj.com/company/products-services/rights-and-licensing/permissions/

BMJ Case Report Fellows may re-use this article for personal use and teaching without any further permission.

Become a Fellow of BMJ Case Reports today and you can:

- Submit as many cases as you like

- Enjoy fast sympathetic peer review and rapid publication of accepted articles

- Access all the published articles

Re-use any of the published material for personal use and teaching without further permission

Customer Service

If you have any further queries about your subscription, please contact our customer services team on +44 (0) 2071111105 or via email at support@bmj.com.

Visit casereports.bmj.com for more articles like this and to become a Fellow 